\title{
The efficacy, safety, and tolerability of levofloxacin quadruple therapy for helicobacter pylori eradication: a randomized, double-blind clinical trial
}

\section{Fariborz Mansour-Ghanaei}

Guilan University of Medical Sciences

\section{Behnam Masihypour}

Guilan University of Medical Sciences

\section{Mohammad Fathalipour}

Hormozgan University of Medical Sciences

\section{Soheil Hassanipour}

Guilan University of Medical Sciences

\section{Homayoon Sokhanvar}

Guilan University of Medical Sciences

\section{Alireza Mansour-Ghanaei}

Guilan University of Medical Sciences

\section{Mehrnaz Asgharnezhad}

Guilan University of Medical Sciences

Farahnaz Joukar ( $\sim$ farajov@gmail.com )

Gasteroentrology and Liver Disease Research Center ,Guilan university of medical science ,Rasht ,Iran

\section{Research article}

Keywords: Helicobacter pylori, levofloxacin, eradication, adverse drug reaction

Posted Date: September 17th, 2020

DOI: https://doi.org/10.21203/rs.3.rs-53307/v1

License: (c) (i) This work is licensed under a Creative Commons Attribution 4.0 International License. Read Full License 


\section{Abstract}

\section{Background}

The incidence of microbial resistance is increasing, and new rescue regimens are needed in order to treat Helicobacter pylori (H. pylori) infection. To evaluate the efficacy, safety, and tolerability of levofloxacin based quadruple therapies in the eradication of $H$. pylori.

Methods

In a randomized, double-blind clinical trial, 220 patients with dyspepsia and $H$. pylori infection were randomly assigned to receive either bismuth subcitrate $240 \mathrm{mg}$, pantoprazole $20 \mathrm{mg}$, amoxicillin $1000 \mathrm{mg}$ twice a day, and levofloxacin $500 \mathrm{mg}$ daily for seven days (BPAL-7), or ten days (BPAL-10). The eradication of $\mathrm{H}$. pylori was evaluated two months after the end of treatment, and adverse drug reactions (ADRs) were assessed during the intervention.

Results

According to intention-to-treat and per-protocol, the eradication rate was significantly lower in the BPAL-7 regimen $49.1 \%$ (95\% Cl: 39.3-57.8) and 47.6\% (95\% Cl: 39.7-58.4), respectively compared to the BPAL10 regimen $62.7 \%$ (95\% Cl: $53.6-72.8)$ and $62.4 \%$ (95\% Cl: 55.1-72.8), respectively. The incidence of ADRs was not statistically significant between BPAL-7 (33.6\%) and BPAL-10 (36.7\%) groups.

Conclusion

Although the ADRs were negligible in both groups, these regimens could not be an ideal alternative therapy for $H$. pylori because of low eradication rates compared to standard regimens.

Trial registration: The study reviewed and approved by the Iranian Registry of Clinical Trials (IRCT201406141155N19). This trial was retrospectively registered on July 10, 2015.

\section{Background}

Helicobacter pylori (H. pylori) affects about $80 \%$ of the total population in developing countries and 20$50 \%$ in developed countries. The infection as a worldwide health problem is associated with acute and chronic gastritis, peptic ulcer disease, and gastric cancer [1-3]. The eradication of $H$. pylori has a main role in the prevention and treatment of these complications $[4,5]$. However, the major concerns of $H$. pylori treatment are low patients compliance, adverse drug reactions (ADRs), and microbial resistance to medicines $[6,7]$.

The efficacy of present pharmacological treatments for $\mathrm{H}$. pylori infection has evaluated in different studies [8-14]. The co-administration of a proton-pump inhibitor (PPI) and two antibiotics (triple therapy), or addition of bismuth salts to the triple therapy (bismuth-based quadruple therapy) for a period of 14 
days are the most common regimens [15]. Among antibacterial agents, amoxicillin or metronidazole, along with clarithromycin, are the first-line treatment for eradication of $H$. pylori $[9,16]$. Nevertheless, microbial resistance is one of the challenging factors of treatment, which causes low efficacy of these regimens. Hence, effective antibiotics should be selected according to the regional pattern of $H$. pylori resistance $[17,18]$.

The prevalence of $H$. pylori infection is relatively high among the Iranian population $[19,20]$. Moreover, novel strains resisted to clarithromycin and metronidazole are prevalent in some geographical part of Iran $[21,22]$. Therefore, a body of evidence suggested new antibiotic regimens with higher efficacy (eradication rate of $>80 \%$ ), lower ADRs and cost, and acceptable patient compliance. The efficacy of levofloxacin as a new-generation quinolone in the treatment of $H$. pylori infection has assessed in several studies, and levofloxacin-containing regimens have shown various eradication rates [23-29].

The current study aimed to evaluate the efficacy, safety, and tolerability of seven- and ten-day period of bismuth subcitrate, pantoprazole, amoxicillin, and levofloxacin regimens in the eradication of $H$. pylori among patients referred to Gastrointestinal Outpatient Clinic of Razi hospital, Rasht, Iran.

\section{Methods}

\section{Trial design}

This study was a phase III open-label, randomized, double-blind controlled trial carried out between July 2015 to November 2015 at Gastrointestinal and Liver Diseases Research Center (GLDRC), Rasht, Iran. All included participants were randomly divided into one of the therapeutic regimens and signed informed consent. The eradication rate of $\mathrm{H}$. pylori was assessed two months after the end of the intervention, and the incidence of ADRs and patient compliance were at the end of treatment.

\section{Ethical consideration}

The protocol of the study was approved by the local ethical committee of Guilan University of Medical Sciences (Ethics committee code; 1930175713), and also performed according to the declaration of Helsinki for human subjects. The study reviewed and approved by the Iranian Registry of Clinical Trials (IRCT201406141155N19).

\section{Patients}

Patients complaining of dyspeptic symptoms referred to the Gastrointestinal Outpatient Clinic of Razi hospital, Rasht, Iran, were enrolled. The main inclusion criteria were a positive rapid urease test and 15 to 65 years of age. Patients with coexisting serious illnesses, including liver cirrhosis, renal failure, heart failure, gastrointestinal malignancies, and history of seizure or hematologic diseases, allergy to medications, and previous incomplete treatment course as well as pregnant or nursing mothers were excluded.

\section{Randomization and intervention}


A block randomization method was used in order to assign patients randomly into permuted treatment blocks and ensure equal numbers in each group of treatment. One of these groups received a seven-day period of bismuth subcitrate $240 \mathrm{mg}$, pantoprazole $20 \mathrm{mg}$, amoxicillin $1000 \mathrm{mg}$ twice a day, and levofloxacin $500 \mathrm{mg}$ daily (BPAL-7), and the other received a ten-day period of the same regimen (BPAL10).

Patients were recommended to take bismuth subcitrate, pantoprazole, and levofloxacin before meals, and amoxicillin after meals at the scheduled times. It also advised avoiding smoking, drinking alcoholic or caffeinated beverages, eating spicy foods, and taking non-steroidal anti-inflammatory drugs or medications containing a monoamine oxidize inhibitor.

Demographic criteria, including age, gender, cigarette smoking, and alcohol drinking, were recorded.

\section{Evaluation of $\mathrm{H}$. pylori eradication}

Two months after the end of the intervention, a Heliprobe ${ }^{14} \mathrm{C}$-Urea Breath Test $\left({ }^{14} \mathrm{C}\right.$-UBT, Kibion $\mathrm{AB}$, Uppsala, Sweden) with a $95 \%$ sensitivity and $100 \%$ specificity was performed to evaluate the $H$. pylori eradication. The treatment success was defined as the result of $<50$ disintegrations per minute (DPM). Taking the medicines were stopped during these two months to avoid interaction with the results of ${ }^{14} \mathrm{C}$ UBT.

\section{Assessment of ADRs and patient compliance}

All patients were informed about potential ADRs, including pyrosis, anorexia, nausea, vomiting, bitter taste, abdominal colic, epigastric pain, headache, and back pain. The ADRs were evaluated during the intervention, using a $0-10$ scoring system (mild: $0-3$, the ADRs exist but insufferable; moderate: 4-6, ADRs sometimes interfere daily life activity; severe: 7-10, ADRs interfere continuously with daily life activities). Acceptable patient compliance was defined as consumption of $>80 \%$ of the prescribed medicines [30].

\section{Statistical analyses}

The eradication rate of two regimens was determined using Intention-to-treat (ITT) and per-protocol (PP) analysis. Patients declined to proceed with the treatment, or those with poor compliance were excluded from PP analysis; however, all patients, including patients who used the treatments out of the protocols or dropouts were included in ITT analysis. The eradication rate of $H$. pylori, odd ratios, and $95 \%$ confidence interval were evaluated for each regimen. Chi-square and $t$ tests were employed to compare qualitative and quantitative variables between two treatment groups, respectively. All statistical analyses were performed using SPSS, version 18.0 software (SPSS Inc, Chicago, IL, United States). A $P<0.05$ was considered statistically significant.

\section{Results}

\section{Characteristics of the patients}


A total of 220 patients with $H$. pylori infection were randomly assigned to either BPAL-7 $(n=110)$ or BPAL$10(n=110)$ groups. Three patients in the BPAL-7 group (one female with severe epigastric pain and diarrhea, and two males with severe anorexia and back pain) and one patient in the BPAL-10 group (one female with severe epigastric pain and nausea) were excluded from the trial because of drug intolerance and low compliance. A flow diagram describing patient selection and study outcomes is shown in Fig. 1.

No significant differences were observed between the two groups in terms of age, gender, cigarette smoking, alcohol drinking $(P>0.05)$. The Basic demographic characteristics of the patients are demonstrated in Table 1.

Table 1

Demographic characteristics of the study patients

\begin{tabular}{|llll|}
\hline Characteristics & $\begin{array}{l}\text { BPAL-7 regimen } \\
(\mathbf{n}=107)\end{array}$ & $\begin{array}{l}\text { BPAL-10 regimen } \\
(\mathbf{n}=109)\end{array}$ & Pvalue \\
\hline Gender, male & $39(36.5)$ & $40(36.7)$ & 0.888 \\
Age & $41.46 \pm 13.25$ & $44.16 \pm 12.70$ & 0.649 \\
\hline Cigarette smoking & $4(3.7)$ & $7(6.4)$ & 0.353 \\
Yes & $103(96.3)$ & $102(93.6)$ & 0.313 \\
No & $1(0.9)$ & $3(2.7)$ & \\
\hline Alcohol drinking & $106(99.1)$ & $106(97.3)$ & \\
Yes & & \\
No & & \\
\hline $\begin{array}{l}\text { Values were demonstrated as numbers (percentages) and Mean } \pm \text { SD for categorical and continuous } \\
\text { variables, respectively. }\end{array}$ & \\
\hline $\begin{array}{l}\text { Chi-square and } t \text { tests were performed to compare categorical and continuous variables between } \\
\text { groups, respectively. }\end{array}$ & \\
\hline $\begin{array}{l}\text { BPAL-7 and BPAL-10; bismuth-based quadruple therapy containing pantoprazole, amoxicillin, and } \\
\text { levofloxacin for seven and ten days, respectively. }\end{array}$ \\
\hline
\end{tabular}

\section{Eradication rates}

The eradication rate of BPAL-7 regimen (49.1\%, 95\% Cl: $39.3-57.8)$ was lower than that of BPAL-10 regimen $(62.7 \%, 95 \% \mathrm{Cl}$ : $53.6-72.8)$ on ITT analysis $(\mathrm{OR}=1.75, \mathrm{P}<0.05)$. Additionally, $\mathrm{PP}$ analysis also demonstrated a lower eradication rate in BPAL-7 regimen $(47.6 \%, 95 \% \mathrm{Cl}$ : $39.7-58.4)$ compared to that of BPAL-10 regimen $(62.4 \%, 95 \% \mathrm{Cl}: 55.1-72.8)(\mathrm{OR}=0.54, \mathrm{P}<0.05)$. The eradication rates of the two regimens are represented in Table 2 . Univariate analyses were shown no association between age, gender, cigarette smoking, and alcohol drinking with an eradication rate of $H$. pylori in both groups $(P>0.05)$. 
Table 2

The eradication rates of the BPAL-7 and BPAL-10 regimens.

\begin{tabular}{|llll|}
\hline Analyses & $\begin{array}{l}\text { BPAL-7 regimen } \\
(\mathbf{n}=107)\end{array}$ & $\begin{array}{l}\text { BPAL-10 regimen } \\
(\mathbf{n = 1 0 9 )})\end{array}$ & Pvalue \\
\hline Intention-to-treat & $54(49.1)$ & $69(62.7)$ & 0.037 \\
\hline Per-protocol & $51(47.6)$ & $68(62.4)$ & 0.024 \\
\hline Values were demonstrated as numbers (percentages). & \\
\hline $\begin{array}{l}{ }^{14} \text { C-urea breath test was conducted to confirm the eradication of } H \text {. pylori two months after the end of } \\
\text { treatment. }\end{array}$ & \\
\hline Chi-square test was performed to compare variables between groups. \\
\hline $\begin{array}{l}\text { BPAL-7 and BPAL-10; bismuth-based quadruple therapy containing pantoprazole, amoxicillin, and } \\
\text { levofloxacin for seven and ten days, respectively. }\end{array}$ \\
\hline
\end{tabular}

\section{ADRs and patient compliances}

Both BPAL-7 and PBAL-10 regimens were well-tolerated by a majority of patients. The number of patients with ADRs was not statistically significant between the BPAL-7 group (36 patients, 33.6\%) and the BPAL10 group (40 patients, $36.7 \%$ ). ADRs were rated as mild (55 patients, $25 \%$ ), moderate (17 patients, $7.7 \%$ ), and severe (4 patients, 1.8\%). The most-reported ADRs were epigastric pain, nausea, vomiting, and bitter taste in both regimens (Table 3 ). 
Table 3

The adverse drug reactions associated with the BPAL-7 and BPAL-10 regimens.

\begin{tabular}{|c|c|c|c|c|c|c|}
\hline \multirow[t]{2}{*}{ ADRs } & \multicolumn{3}{|c|}{ BPAL-7 $(n=107)$} & \multicolumn{3}{|c|}{ BPAL-10 $(n=109)$} \\
\hline & Mild & Moderate & Severe & Mild & Moderate & Severe \\
\hline Pyrosis & $31(29.0)$ & $4(3.7)$ & $1(0.9)$ & $23(21.1)$ & $10(9.2)$ & $1(0.9)$ \\
\hline Anorexia & $25(23.4)$ & $4(3.7)$ & $2(1.9)$ & $21(19.3)$ & $4(3.7)$ & $1(0.9)$ \\
\hline Nausea & $19(17.8)$ & $2(1.8)$ & $1(0.9)$ & $25(22.9)$ & $0(0.0)$ & $0(0.0)$ \\
\hline Vomiting & $2(1.9)$ & $1(0.9)$ & $0(0.0)$ & $0(0.0)$ & $0(0.0)$ & $1(0.9)$ \\
\hline Bitter taste & $19(17.8)$ & $0(0.0)$ & $1(0.9)$ & $10(9.2)$ & $2(1.8)$ & $1(0.9)$ \\
\hline Abdominal colic & $12(11.2)$ & $0(0.0)$ & $0(0.0)$ & $9(8.2)$ & $3(2.7)$ & $0(0.0)$ \\
\hline Epigastric pain & $17(15.9)$ & $7(6.5)$ & $1(0.9)$ & $22(20.2)$ & $3(2.7)$ & $1(0.9)$ \\
\hline Headache & $15(14.0)$ & $2(1.9)$ & $1(0.9)$ & $16(14.7)$ & $7(6.4)$ & $1(0.9)$ \\
\hline Back pain & $6(5.6)$ & $1(0.9)$ & $2(1.9)$ & $9(8.3)$ & $6(5.5)$ & $1(0.9)$ \\
\hline \multicolumn{7}{|c|}{ Values were demonstrated as numbers (percentages). } \\
\hline \multicolumn{7}{|c|}{ Adverse drug reactions were evaluated during the study. } \\
\hline \multicolumn{7}{|c|}{$\begin{array}{l}\text { Chi-square test was performed to compare variables between groups. None of variables were shown } \\
\text { statistically significant differences between two regimens in each category. }\end{array}$} \\
\hline
\end{tabular}

The compliance rates were $97.3 \%$ and $99.1 \%$ for the BPAL-7 and PBAL-10 regimens, respectively. Three patients in the BPAL-7 regimen and one patient in the PBAL-10 regimen excluded from the PP analysis because of failure to ingest $>80 \%$ of the medications.

\section{Discussion}

The finding of the present study showed a lower rate of $H$. pylori eradication in the BPAL-7 regimen compared to the BPAL-10 regimen among patients with dyspepsia and H. pylori infection. Both BPAL-7 and PBAL-10 regimens were well-tolerated and had acceptable patient compliance.

Recent guidelines suggest the eradication rate of triple therapy with a PPI, amoxicillin or metronidazole, and clarithromycin as first-line regimens have decreased, particularly due to an increase in microbial resistance to clarithromycin [1]. Moreover, some recommended bismuth-based quadruple therapy regimens also have an eradication rate of less than $80 \%$ [31]. Therefore, more effective regimens are needed to eradicate the $H$. pylori infection. 
A body of evidence suggested to using levofloxacin, a new generation fluoroquinolone with in vitro anti- $H$. pylori activity, as an alternative agent in clarithromycin-resistant cases. Levofloxacin containing triple, quadruple, and sequential regimens have demonstrated a various range of eradication rates [32-34].

A study compared a triple therapy consisting of esomeprazole, levofloxacin (500 mg daily), and amoxicillin with a standard regimen consist of esomeprazole, metronidazole, bismuth, and tetracycline for a period of 14 days. The eradication rate of levofloxacin containing regimen (96.3\%) was higher than the standard regimen (86.0\%) in ITT analysis [24].

Gisbert et al. from Spain demonstrated the eradication rate of ranitidine bismuth citrate, levofloxacin, and amoxicillin as first-line triple therapy for $\mathrm{H}$. pylori was 84.4 and ADRs, mainly including diarrhea, were reported in $9.5 \%$ of the patients [35]. This group carried out a trial with 1000 patients on the efficacy of omeprazole, levofloxacin, and amoxicillin for ten days. They reported an eradication rate of $73.8 \%$ and ADRs of $20 \%$, which most commonly included nausea, metallic taste, and abdominal pain [25]. The dosage of levofloxacin was higher in these studies (500 mg twice a day). In a recent multicenter study conducted by Gisbert et al., 14 days treatment by esomeprazole, amoxicillin, levofloxacin ( $500 \mathrm{mg}$ daily), and bismuth as a rescue therapy achieved more than $90 \%$ of eradiation rate [26]. In another Spanish study, the eradication rate of omeprazole, levofloxacin (500 mg twice a day), and amoxicillin combination for a ten-day period also had about $20 \%$ failure rate [36].

A study from Kosovo randomized 105 patients to either seven or ten days levofloxacin-based regimens, including omeprazole, levofloxacin (500 mg daily), and amoxicillin. The eradication rates were $86.2 \%$ and $93.6 \%$, respectively. About $5 \%$ of patients experienced ADRs, mostly nausea and diarrhea [27].

Several Taiwanese studies evaluated the efficacy of levofloxacin-containing regimens as rescue therapy for the eradication of $H$. pylori. Kuo et al. reported the eradication rate of esomeprazole, amoxicillin, and levofloxacin (500 mg daily) regimen for seven days is similar to a second line quadruple standard regimens (about 60-70\%) [37]. Four years later, the same group published a study comparing a levofloxacin-containing quadruple therapy (esomeprazole, bismuth, tetracycline, and $500 \mathrm{mg}$ of levofloxacin once daily) for ten days with high-dose metronidazole- containing standard quadruple regimen. Based on their findings, eradication rates of about $80 \%$ was reached for both regimens [38]. On the other hand, Hsu et al. showed a ten-day quadruple therapy consist of esomeprazole, bismuth, tetracycline, and levofloxacin (500 mg daily) achieved a very high eradication rate (95.8\%) at this geographical area. ADRs were detected in $25.0 \%$ of patients [39]. In another study, the efficacy of adding bismuth to a levofloxacin-based triple regimen (rabeprazole, bismuth, amoxicillin, and $500 \mathrm{mg}$ of levofloxacin daily) assessed. The results revealed no further significant eradication rat (67.6\%), but no more ADRs were noted [40].

According to the results of the present study, the BPAL-7 and the PBAL-10 regimens were not clinically successful in the treatment of $H$. pylori with an eradication rate of $62.7 \%$ and $49.1 \%$ by ITT analyses, respectively. Both regimens achieved neither cut point of an ideal regimen (eradication rate of $>90 \%$ ), nor acceptable eradication rate of Maastricht and other guidelines (> $80 \%$ ) [41]. The low efficacy of these 
regimens is likely related to the regional pattern of bacterial resistance. The results of these regimens are consistent with a previous Iranian study evaluating the efficacy of a 14-day triple therapy, comprised of omeprazole, levofloxacin (500 mg daily), amoxicillin with success rate of 75\% [42]. However, studies conducted in other parts of Iran revealed fluoroquinolone-containing regimens including a 14-day of omeprazole, levofloxacin (250 mg twice a day) and amoxicillin as well as a 14-day of omeprazole, levofloxacin (500 mg twice a day), and amoxicillin as rescue therapies of $H$. pylori had eradication rate of $90 \%$ and $86.7 \%$, respectively $[43,44]$. Moreover, there are some other Iranian investigations that evaluated the efficacy of levofloxacin-based, sequential therapy in the treatment of $H$. pylori, and the eradication rate ranged from $70.8 \%$ to $85.1 \%$ [45-47].

No relationship was observed between patient demographic characteristics including age, gender, cigarette smoking, and alcohol drinking and the success rate of both BPAL-7 and PBAL-10 regimens. Previous studies have also demonstrated the eradication rate of levofloxacin-containing regimens was not associated with age $[45,47,44]$, gender $[46,45,44]$, smoking status [48, 45], and education level [45].

Although high efficacy along with compatibility with the pattern of regional bacterial resistance are the main properties of an ideal pharmacological regimen for eradication of $H$. pylori, tolerability, patient compliance, simplicity, and cost-efficacy should not be neglected [30]. The compliance rates for the BPAL7 and PBAL-10 regimens were $97.3 \%$ and $99.1 \%$, respectively. In spite of high compliance rats, ADRs were reported in one-third of patients. The most-reported ADRs were epigastric pain, nausea, vomiting, and bitter taste. Generally, BPAL-7 and PBAL-10 regimens were patient compatible and well-tolerated.

\section{Limitations}

The main limitations of the present study are the lack of regional pattern of antibiotic resistance and a local estimate of $H$. pylori eradication rate as well as the small number of patients in the groups. The absence of pretreatment susceptibility assessment to levofloxacin is another drawback. Moreover, the finding may not be applicable to patients with previous treatment failure and recurrence disease.

\section{Conclusion}

The BPAL-7 and PBAL-10 regimens were patient compatible and well-tolerated. However, both regimens showed no satisfied eradication rate. Therefore, these regimens could not be ideal alternative therapies for $H$. pylori eradication in this region. It is better to evaluate the efficacy and tolerability of this regimen in other geographical regions, longer studies with more sample size.

\section{Abbreviations}

H. pylori: Helicobacter pylori, ADRs:adverse drug reactions; PPI:proton-pump inhibitor; ITT; intention-totreat, PP; per-protocol, BPAL-7:bismuth-based quadruple therapy containing pantoprazole, amoxicillin, and levofloxacin for seven days; BPAL-10; bismuth-based quadruple therapy containing pantoprazole, amoxicillin, and levofloxacin for ten days 


\section{Declarations}

\section{Availability of data and materials}

The datasets generated during the current study are available from the corresponding author on reasonable request.

\section{Ethics approval and consent to participate}

All participants provided their written informed consent to participate in this study. For participants under 16 years of age, the consent form was completed by the parents. The study protocol was approved by Ethics Committee of Guilan University of Medical Sciences, Rasht, Iran.

\section{Consent for publication}

Not applicable.

\section{Competing interests}

The authors report no conflicts of interest in this work.

\section{Funding}

The study was financially supported by a grant from Guilan University of Medical Sciences, Rasht, Iran (grant number: 1930175713). Our organization has helped us to provide principal materials and drugs.

\section{Authors' contribution}

FJ and FMG designed and supervised the procedure of the research. FMG, MA, HS, and BM enrolled participants, collected data. FJ, SH, and MS analyzed data, and MF, FJ, MA, AMG and MS drafted the manuscript. MF, AMG and MA edited and revised the manuscript. All authors have read and approved the final draft of the paper.

\section{Acknowledgments}

The authors would especially like to thank the assistance and cooperation of the Health Deputy of Gastrointestinal and Liver Diseases Research Center (GLDRC) of Guilan University of Medical Sciences, Rasht, Iran. This study supported by Guilan University of Medical Sciences, Rasht, Iran.

\section{References}


1. Chey WD, Wong BC. American College of Gastroenterology guideline on the management of Helicobacter pylori infection. Am J Gastroenterol. 2007;102(8):1808-25. doi:10.1111/j.15720241.2007.01393.x.

2. Fock KM, Katelaris P, Sugano K, Ang TL, Hunt R, Talley NJ, Lam SK, Xiao S, Tan HJ, Wu CY. Second Asia-Pacific consensus guidelines for Helicobacter pylori infection. J Gastroenterol Hepato. 2009;24(10):1587-600.

3. Shafaie S, Kaboosi H, Peyravii Ghadikolaii F. Prevalence of non Helicobacter pylori gastric Helicobacters in Iranian dyspeptic patients. BMC Gastroenterol. 2020;20(1):190-0. doi:10.1186/s12876-020-01331-x.

4. Khatibian M, Ajvadi Y, Nasseri-Moghaddam S, Ebrahimi-Dariani N, Vahedi H, Zendehdel N, Sotoudehmanesh R, Agah S, Mikaeli J, Pourshams A, Ali-Asgari A, Malekzadeh R, Massarrat S. (2007) Furazolidone-based, metronidazole-based, or a combination regimen for eradication of Helicobacter pylori in peptic ulcer disease. Arch Iran Med 10 (2):161-167. doi:07102/AIM.007.

5. Malfertheiner P, Megraud F, O'morain CA, Atherton J, Axon A, Bazzoli F, Gensini GF, Gisbert JP, Graham DY, Rokkas T. Management of Helicobacter pylori infection-the Maastricht IV/Florence consensus report. Gut. 2012;61(5):646-64.

6. Karatapanis S, Skorda L, Georgopoulos S, Papantoniou N, Papastergiou V, Ntoutsikos K, Komnianides K, Lisgos PH. Levofloxacin-based triple therapy versus bismuth-based quadruple therapy as a second line treatment for the eradication of $H$. pylori infection. Ann Gastroenterol. 2009;22(4):263-7.

7. Wu W, Yang Y, Sun G. (2012) Recent insights into antibiotic resistance in Helicobacter pylori eradication. Gastroent Res and Pract 2012 (1):723183.

8. Fischbach LA, van Zanten S, Dickason J. Meta-analysis: the efficacy, adverse events, and adherence related to first-line anti-Helicobacter pylori quadruple therapies. Aliment Pharmacol Ther. 2004;20(10):1071-82. doi:10.1111/j.1365-2036.2004.02248.x.

9. Gisbert JP, Gonzalez L, Calvet X, Garcia N, Lopez T, Roque M, Gabriel R, Pajares JM. Proton pump inhibitor, clarithromycin and either amoxycillin or nitroimidazole: a meta-analysis of eradication of Helicobacter pylori. Aliment Pharmacol Ther. 2000;14(10):1319-28. doi:10.1046/j.13652036.2000.00844.x.

10. Ahn HJ, Kim DP, Chu MS, Yun HJ, Kim SH, Lee SW, Lee DS. (2017) Efficacy and Safety of the Triple Therapy Containing Ilaprazole, Levofloxacin, and Amoxicillin as First-Line Treatment in Helicobacter pylori Infections. Gastroenterol Res Pract:6. doi:10.1155/2017/1654907.

11. Tai WC, Chiu CH, Liang CM, Chang KC, Kuo CM, Chiu YC, Wu KL, Hu ML, Chou YP, Chiou SS, Chiu KW, Kuo CH, Hu TH, Lin MT, Chuah SK. (2013) Ten-Day versus 14-Day Levofloxacin-Containing Triple Therapy for Second-Line Anti-Helicobacter pylori Eradication in Taiwan. Gastroenterol Res Pract:6. doi:10.1155/2013/932478.

12. Ohno A, Miyoshi J, Kato A, Miyamoto N, Yatagai T, Hada Y, Kusuhara M, Jimbo Y, Ida Y, Tokunaga K, Okamoto S, Hisamatsu T. Endoscopic severe mucosal atrophy indicates the presence of gastric 
cancer after Helicobacter pylori eradication -analysis based on the Kyoto classification. BMC Gastroenterol. 2020;20(1):232. doi:10.1186/s12876-020-01375-z.

13. Song Z, Fu W, Zhou L. Cefuroxime, levofloxacin, esomeprazole, and bismuth as first-line therapy for eradicating Helicobacter pylori in patients allergic to penicillin. BMC Gastroenterol. 2019;19(1):132. doi:10.1186/s12876-019-1056-3.

14. Kabakambira JD, Hategeka C, Page C, Ntirenganya C, Dusabejambo V, Ndoli J, Ngabonziza F, Hale D, Bayingana C, Walker T. Efficacy of Helicobacter pylori eradication regimens in Rwanda: a randomized controlled trial. BMC Gastroenterol. 2018;18(1):134. doi:10.1186/s12876-018-0863-2.

15. Graham DY, Lee S-Y. How to Effectively Use Bismuth Quadruple Therapy: The Good, the Bad, and the Ugly. Gastroenterol Clin North Am. 2015;44(3):537-63. doi:10.1016/j.gtc.2015.05.003.

16. Mansour-Ghanaei F, Samadi A, Joukar F, Tirgar Fakheri H, Hassanipour S, Ashoobi MT, Soltanipour S, Alizadeh A, Rezamand G, Fathalipour M. Efficacy and tolerability of fourteen-day sequential quadruple regimen: pantoprazole, bismuth, amoxicillin, metronidazole and or furazolidone as firstline therapy for eradication of Helicobacter pylori: a randomized, double-blind clinical trial. EXCLI J. 2019;18(1):644-52. doi:10.17179/excli2019-1613.

17. Megraud F. H pylori antibiotic resistance: prevalence, importance, and advances in testing. Gut. 2004;53(9):1374-84. doi:10.1136/gut.2003.022111.

18. Graham DY, Qureshi WA. Antibiotic-resistant H. pylori infection and its treatment. Curr Pharm Design. 2000;6(15):1537-44. doi:10.2174/1381612003399077.

19. Jafar S, Jalil A, Soheila N, Sirous S. Prevalence of helicobacter pylori infection in children, a population-based cross-sectional study in west iran. Iran J Pediatr. 2013;23(1):13-8.

20. Nouraie M, Latifi-Navid S, Rezvan H, Radmard AR, Maghsudlu M, Zaer-Rezaii H, Amini S, Siavoshi F, Malekzadeh R. Childhood hygienic practice and family education status determine the prevalence of Helicobacter pylori infection in Iran. Helicobacter. 2009;14(1):40-6. doi:10.1111/j.15235378.2009.00657.x.

21. Salmanroghani H, Mirvakili M, Baghbanian M, Salmanroghani R, Sanati G, Yazdian P. Efficacy and Tolerability of Two Quadruple Regimens: Bismuth, Omeprazole, Metronidazole with Amoxicillin or Tetracycline as First-Line Treatment for Eradication of Helicobacter Pylori in Patients with Duodenal Ulcer: A Randomized Clinical Trial. PloS one. 2018;13(6):e0197096. doi:10.1371/journal.pone.0197096.

22. Ebrahimi-Dariani N, Mirmomen S, Mansour-Ghanaei F, Noormohammadpoor P, Sotodehmanesh R, Haghpanah B, Bahrami $\mathrm{H}$. The efficacy of furazolidone-based quadruple therapy for eradication of Helicobacter pylori infection in Iranian patients resistant to metronidazole-based quadruple therapy. Medical science monitor: international medical journal of experimental clinical research. 2003;9(8):PI105-108.

23. An B, Moon BS, Kim H, Lim HC, Lee YC, Lee G, Kim SH, Park M, Kim JB. Antibiotic resistance in Helicobacter pylori strains and its effect on $H$. pylori eradication rates in a single center in Korea. Ann Lab Med. 2013;33(6):415-9. doi:10.3343/alm.2013.33.6.415. 
24. Chuah S, Tai W, Hsu P, Wu D, Wu K, Kuo C, Chiu Y, Hu M, Chou Y, Kuo Y. The efficacy of second-line anti-Helicobacter pylori therapy using an extended 14-day levofloxacin/amoxicillin/proton-pump inhibitor treatment-a pilot study. Helicobacter. 2012;17(5):374-81.

25. Gisbert JP, Perez-Aisa A, Bermejo F, Castro-Fernandez M, Almela P, Barrio J, Cosme A, Modolell I, Bory F, Fernandez-Bermejo M, Rodrigo L, Ortuno J, Sanchez-Pobre P, Khorrami S, Franco A, Tomas A, Guerra I, Lamas E, Ponce J, Calvet X. Second-line therapy with levofloxacin after failure of treatment to eradicate helicobacter pylori infection: time trends in a Spanish Multicenter Study of 1000 patients. J Clin Gastroenterol. 2013;47(2):130-5. doi:10.1097/MCG.0b013e318254ebdd.

26. Gisbert JP, Romano M, Gravina AG, Solís-Muñoz P, Bermejo F, Molina-Infante J, Castro-Fernández M, Ortuño J, Lucendo AJ, Herranz M. Helicobacter pylori second-line rescue therapy with levofloxacinand bismuth-containing quadruple therapy, after failure of standard triple or non-bismuth quadruple treatments. Aliment Pharmacol Ther. 2015;41(8):768-75.

27. Telaku S, Manxhuka-Kerliu S, Kraja B, Qirjako G, Prifti S, Ejza H. The efficacy of levofloxacin -based triple therapy for first -line Helicobacter pylori eradication. Medical Archives. 2013;67(1):348-50.

28. Chang S-P, Lee H-Z, Lai C-C, Tang H-J. The efficacy and safety of nemonoxacin compared with levofloxacin in the treatment of community-acquired pneumonia: a systemic review and metaanalysis of randomized controlled trials. Infect Drug Resist. 2019;12:433-8. doi:10.2147/IDR.S193233.

29. Chen C-W, Chen Y-H, Cheng I-L, Lai C-C. Comparison of high-dose, short-course levofloxacin treatment vs conventional regimen against acute bacterial infection: meta-analysis of randomized controlled trials. Infect Drug Resist. 2019;12:1353.

30. Malfertheiner P, Megraud F, O'Morain C, Bazzoli F, El-Omar E, Graham D, Hunt R, Rokkas T, Vakil N, Kuipers EJ. Current concepts in the management of Helicobacter pylori infection: the Maastricht III Consensus Report. Gut. 2007;56(6):772-81. doi:10.1136/gut.2006.101634.

31. Venerito M, Krieger T, Ecker T, Leandro G, Malfertheiner P. Meta-analysis of bismuth quadruple therapy versus clarithromycin triple therapy for empiric primary treatment of Helicobacter pylori infection. Digestion. 2013;88(1):33-45. doi:10.1159/000350719.

32. Chen PY, Wu MS, Chen CY, Bair MJ, Chou CK, Lin JT, Liou JM. Systematic review with meta-analysis: the efficacy of levofloxacin triple therapy as the first- or second-line treatments of Helicobacter pylori infection. Aliment Pharmacol Ther. 2016;44(5):427-37. doi:10.1111/apt.13712.

33. Xiao SP, Gu M, Zhang GX. Is levofloxacin-based triple therapy an alternative for first-line eradication of Helicobacter pylori? A systematic review and meta-analysis. Scand J Gastroenterol. 2014;49(5):528-38. doi:10.3109/00365521.2014.887765.

34. Ye CL, Liao GP, He S, Pan YN, Kang YB, Zhang ZY. Levofloxacin and proton pump inhibitor-based triple therapy versus standard triple first-line therapy for Helicobacter pylori eradication. Pharmacoepidemiol Drug Saf. 2014;23(5):443-55. doi:10.1002/pds.3581.

35. Gisbert JP, Fernandez-Bermejo M, Molina-Infante J, Perez-Gallardo B, Prieto-Bermejo AB, MateosRodriguez JM, Robledo-Andres P, Gonzalez-Garcia G. First-line triple therapy with levofloxacin for 
Helicobacter pylori eradication. Aliment Pharmacol Ther. 2007;26(3):495-500. doi:10.1111/j.13652036.2007.03384.x.

36. Molina-Infante J, Perez-Gallardo B, Fernandez-Bermejo M, Hernandez-Alonso M, Vinagre G, Duenas C, Mateos-Rodriguez JM, Gonzalez-Garcia G, Abadia EG, Gisbert JP. Clinical trial: clarithromycin vs. levofloxacin in first-line triple and sequential regimens for Helicobacter pylori eradication. Aliment Pharmacol Ther. 2010;31(10):1077-84. doi:10.1111/j.1365-2036.2010.04274.x.

37. Kuo CH, Hu HM, Kuo FC, Hsu PI, Chen A, Yu FJ, Tsai PY, Wu IC, Wang SW, Li CJ, Weng BC, Chang LL, Jan CM, Wang WM, Wu DC. Efficacy of levofloxacin-based rescue therapy for Helicobacter pylori infection after standard triple therapy: a randomized controlled trial. J Antimicrob Chemother. 2009;63(5):1017-24. doi:10.1093/jac/dkp034.

38. Kuo CH, Hsu PI, Kuo FC, Wang SS, Hu HM, Liu CJ, Chuah SK, Chen YH, Hsieh MC, Wu DC, Tseng HH. Comparison of 10 day bismuth quadruple therapy with high-dose metronidazole or levofloxacin for second-line Helicobacter pylori therapy: a randomized controlled trial. J Antimicrob Chemother. 2013;68(1):222-8. doi:10.1093/jac/dks361.

39. Hsu PI, Chen WC, Tsay FW, Shih CA, Kao SS, Wang HM, Yu HC, Lai KH, Tseng HH, Peng NJ, Chen A, Kuo $\mathrm{CH}$, Wu DC. Ten-day Quadruple therapy comprising proton-pump inhibitor, bismuth, tetracycline, and levofloxacin achieves a high eradication rate for Helicobacter pylori infection after failure of sequential therapy. Helicobacter. 2014;19(1):74-9. doi:10.1111/hel.12085.

40. Wu TS, Hsu PI, Kuo CH, Hu HM, Wu IC, Wang SSW, Chen YH, Wu DC, Su WW, Kuo FC. Comparison of 10-day levofloxacin bismuth-based quadruple therapy and levofloxacin-based triple therapy for Helicobacter pylori. Journal of digestive diseases. 2017;18(9):537-42. doi:10.1111/17512980.12498.

41. Gao XZ, Qiao XL, Song WC, Wang XF, Liu F. Standard triple, bismuth pectin quadruple and sequential therapies for Helicobacter pylori eradication. World journal of gastroenterology. 2010;16(34):435762. doi:10.3748/wjg.v16.i34.4357.

42. Haji-Aghamohammadi AA, Bastani A, Miroliaee A, Oveisi S, Safarnezhad S. Comparison of levofloxacin versus clarithromycin efficacy in the eradication of Helicobacter pylori infection. Caspian J Intern Med. 2016;7(4):267-71.

43. Abangah G, Raughani A, Asadollahi P, Asadollahi K. (2019) Comparison between the two drug regimens of $\mathrm{PPI}+$ Amoxicillin + Rifampicin and PPI + Amoxicillin + Levofloxacin for the treatment of $\mathrm{H}$. pylori infections resistant to the first line drug regimen among patients referred to llam clinics. Gastroenterology and hepatology from bed to bench 12 (3):209-216.

44. Seyyedmajidi M, Abbasi L, Seyedmajidi S, Hosseini SA, Ahmadi A, Hajiebrahimi S, Vafaeimanesh J. Levofloxacin-containing triple therapy versus bismuth-based quadruple therapy as regimens for second line anti- Helicobacter pylori. Caspian J Intern Med. 2019;10(2):211-6. doi:10.22088/cjim.10.2.211.

45. Moradniani M, Mirbeik-Sabzevari Z, Jaferian S, Shafiezadeh S, Ehsani Ardakani MJ, Mirzaee Roozbahany M, Azadbakht S, Sherkatolabbasieh H. (2018) Levofloxacin based vs clarithromycin 
based sequential therapy in helicobacter pylori eradication; a randomized clinical trial. Gastroenterology and hepatology from bed to bench 11 (1):19-26.

46. Hajiani E, Alavinejad P, Avandi N, Masjedizadeh AR, Shayesteh AA. Comparison of LevofloxacinBased, 10-day Sequential Therapy with 14-day Quadruple Therapy for Helicobacter Pylori Eradication: A Randomized Clinical Trial. Middle East J Dig Dis. 2018;10(4):242-8. doi:10.15171/mejdd.2018.117.

47. Sebghatollahi V, Soheilipour M, Khodadoostan M, Shavakhi A, Shavakhi A. Levofloxacin-containing versus Clarithromycin-containing Therapy for Helicobacter pylori Eradication: A Prospective Randomized Controlled Clinical Trial. Advanced biomedical research. 2018;7(1):55-67. doi:10.4103/abr.abr_133_17.

48. Chuah SK, Tai WC, Hsu PI, Wu DC, Wu KL, Kuo CM, Chiu YC, Hu ML, Chou YP, Kuo YH, Liang CM, Chiu $\mathrm{KW}, \mathrm{Hu} \mathrm{TH}$. The efficacy of second-line anti-Helicobacter pylori therapy using an extended 14-day levofloxacin/amoxicillin/proton-pump inhibitor treatment-a pilot study. Helicobacter. 2012;17(5):374-81. doi:10.1111/j.1523-5378.2012.00960.x.

\section{Figures}
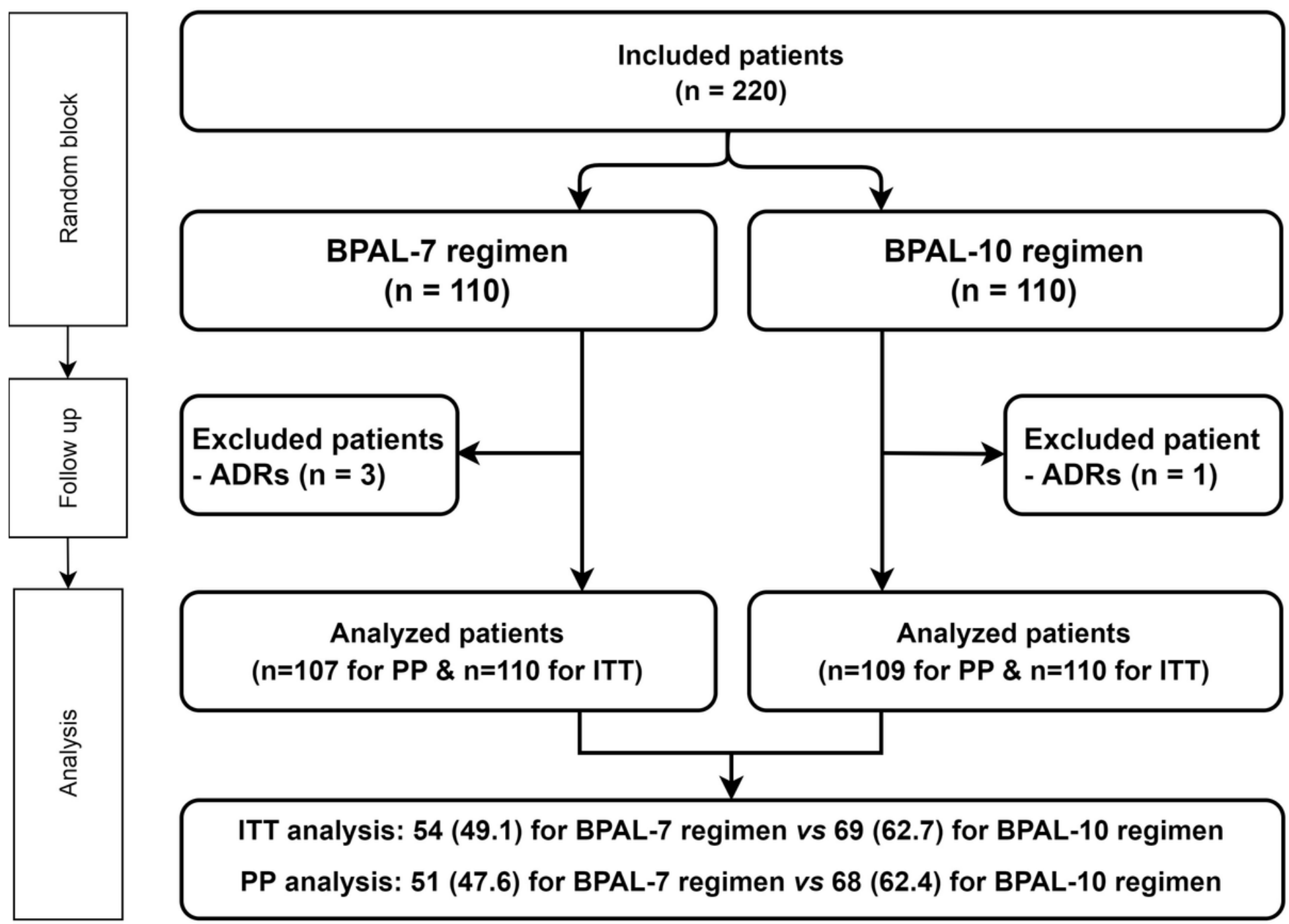


\section{Figure 1}

Flow chart for process of patient randomization. ITT; intention-to-treat, PP; per-protocol, ADRs; adverse drug reactions, BPAL-7 and BPAL-10; bismuth-based quadruple therapy containing pantoprazole, amoxicillin, and levofloxacin for seven and ten days, respectively.

\section{Supplementary Files}

This is a list of supplementary files associated with this preprint. Click to download.

- CONSORTChecklist.doc 